\title{
Chemical Constituents of the Femoral Gland Secretions of Male Tegu Lizards (Tupinambis merianae) (Family Teiidae)
}

\author{
José Martín ${ }^{\mathrm{a}, *}$, Silvia Chamut ${ }^{\mathrm{b}}$, Mario E. Manes ${ }^{\mathrm{b}}$, and Pilar López \\ a Departamento de Ecología Evolutiva, Museo Nacional de Ciencias Naturales, CSIC, \\ José Gutiérrez Abascal 2, 28006 Madrid, Spain. Fax: 34-91-5 645078. \\ E-mail: Jose.Martin@mncn.csic.es \\ b Facultad de Agronomía y Zootecnia, Universidad Nacional de Tucumán, \\ F. Ameghino s/n, El Manantial (4105), Tucumán, Argentina \\ * Author for correspondence and reprint requests \\ Z. Naturforsch. 66 c, 434-440 (2011); received December 2, 2010/March 25, 2011
}

In spite of the importance of chemical signals (pheromones) in the reproductive behaviour of lizards, the chemical compounds secreted by their femoral glands, which may be used as sexual signals, are only known for a few lizard species. Based on mass spectra, obtained by GC-MS, we found 49 lipophilic compounds in femoral gland secretions of male tegu lizards (Tupinambis merianae) (fam. Teiidae), including a very high proportion of carboxylic acids and their esters ranging between $n-\mathrm{C}_{8}$ and $n-\mathrm{C}_{20}$ (mainly octadecanoic and 9,12-octadecadienoic acids), with much less proportions of steroids, tocopherol, aldehydes, and squalene. We discuss the potential function of these compounds in secretions, and compare the compounds found here with those documented for other lizard species.

Key words: Tegu Lizard, Femoral Glands, Fatty Acids, Steroids

\section{Introduction}

Chemical signals are important in intraspecific communication and sexual selection of many reptiles (Mason, 1992; Mason and Parker, 2010; Martín and López, 2011). Males of many lizard species secrete chemical compounds from the femoral or precloacal glands (Alberts, 1993; Weldon et al., 2008) that may function as pheromones (Mason and Parker, 2010; Martín and López, 2011). Multiple pheromone compounds in femoral gland secretions seem to inform about the characteristics and health state of a male (López et al., 2006; Martín et al., 2007a). This information may be used by females to select scent marks of some individual males, which suggests pheromonal mate choice (e.g., Martín and López, 2000, 2006a; López et al., 2002, 2003; Olsson et al., 2003; López and Martín, 2005a). Compounds in femoral gland secretions may also provide information on fighting ability or dominance status to other males (Aragón et al., 2001; Carazo et al., 2007; Martín et al., 2007b).

Femoral gland secretions are composed of both lipids and proteins, but some specific lipophilic compounds (i.e. steroids and fatty acids) seem to be the main compounds involved in pheromonal communication (Mason, 1992; Martín and López, 2006a, 2010a, 2011). Although the types of com- pounds in secretions are similar in different lizard species, the presence and abundance of specific compounds vary widely between species (Weldon et al., 2008), which might be due to phylogenetic or environmental differences (Alberts, 1992; Escobar et al., 2003; Martín and López, 2006b). However, the chemical composition of femoral gland secretions has been analysed in only a few lizard species (reviewed in Weldon et al., 2008). Most information relates to European lizards of the family Lacertidae (López and Martín, 2005b, c, 2006, 2009; Martín and López, 2006b, c, 2010b; Gabirot el al., 2008; Kopena et al., 2009), American lizards of the families Iguanidae (Weldon et al., 1990; Alberts et al., 1992) and Liolaemidae (Escobar et al., 2001, 2003), and an African cordylid lizard (Louw et al., 2007). However, there are many lizard species within other taxonomic lineages and geographical areas that have femoral pores with abundant secretions, which have never been chemically analysed, in spite of secretions being often related to chemical communication (see reviews by Weldon et al., 2008; Mason and Parker, 2010). To understand the composition and role of femoral gland secretions of lizards, we need more studies that deal with a wider range of lizard taxa and consider a larger variety of environmental conditions. 
The tegu lizards of the genus Tupinambis (Sauria: Teiidae) comprise a group of carnivorous lizards of large size (adult body weight of up to $8 \mathrm{~kg}$ ) that inhabit the South American plain, east of the Andes (Presch, 1973; Fitzgerald et al., 1999). One of the southernmost species is the Argentine black and white tegu, Tupinambis merianae (formerly T. teguixin) (Cei and Scolaro, 1982). This lizard has well developed femoral glands, but secretions are only found in males during the short mating season that occurs around October (Noriega et al., 2002; Manes et al., 2007; Chamut et al., 2009). The discharges of each gland unit merge into a solid cylinder of secretion, surrounded by epithelial cells, which is extruded to the exterior (Chamut et al., 2009). There are no specific studies on the role of chemical cues in reproduction of tegu lizards, but these lizards show a series of distinctive reproductive behaviours, including characteristic territorial scent marking (Mercolli and Yanosky, 1989; Fitzgerald et al., 1991; Noriega et al., 1996). During scent-marking, males typically rub their thighs and cloacal region on the ground (Mercolli and Yanosky, 1989; Fitzgerald et al., 1991; Noriega et al., 1996). This behaviour abrades the secretion cylinders from the femoral glands, leaving a trail of odour on the soil (Chamut et al., 2009). The tongue-flicking responses and the overlapping of territorial scent marks, when some males were replaced by others, indicate the presence and response to secretions on the substrate (Chamut et al., 2009). All these observations suggest that femoral glands play an important role in the reproductive behaviour of tegu lizards, presumably by releasing pheromones.

In T. merianae, the weak staining of cells in the femoral glands by Sudan Red indicates the presence of lipids in the secretion (Chamut et al., 2009). However, the chemical compounds in femoral gland secretions of this lizard are unknown. Moreover, there are no studies on the chemical composition of any lizard species belonging to the family Teiidae. In the present paper, we report the results of an analysis by gas chromatography-mass spectrometry (GC-MS) of the lipophilic fraction of femoral gland secretions of male tegu lizards (T. merianae) from an Argentinean population.

\section{Material and Methods}

We collected femoral gland secretions from eight adult male T. merianae, between 2 and 7 years old, during October 2009, coinciding with the mating season. Lizards came from the breeding colony of the experimental farm at the Faculty of Agronomy and Zootecnia of the National University of Tucumán in Northern Argentina. Original specimens were captured in the province of Santa Fe (centre Argentina) and donated to us by the "El Gringo" hatchery (Sa Pereira, Province of Santa Fe, Argentina). The breeding stock consisted of groups of one male and five or six females, housed in open-air pens. The pens were surrounded by masonry walls, $1.2 \mathrm{~m}$ high; each pen contained a shelter, which provided shade and allowed each individual an area of $2 \mathrm{~m}^{2}$. The animals were fed ad libitum with a hatchery diet (Vega Parry and Manes, 2000). The lizards were weighed [body mass, $(4.46 \pm 0.98) \mathrm{kg}$; range, $3.36-6.85 \mathrm{~kg}$ ] and their snout-vent length $(\mathrm{SVL})$ was measured $[(44.81 \pm 3.15) \mathrm{cm}$; range, $42-52.5 \mathrm{~cm}]$. The lizards had an average of $24 \pm 2$ (range, 22-26) femoral pores on each leg.

We extracted the secretion cylinders from the femoral pores of the lizards using slim pliers, and kept the secretions in glass vials closed with Teflon-lined stoppers. Vials were stored at $-20{ }^{\circ} \mathrm{C}$ until analyses. We also used the same procedure, but without collecting secretion, to obtain blank control vials that were treated in the same manner to compare with the lizards samples to be able to exclude contaminants from the handling procedure and for examining impurities in the solvent.

We analysed the samples with a ThermoQuest (Austin, TX, USA) Trace 2000 gas chromatograph fitted with a poly $(5 \%$ diphenyl $/ 95 \%$ dimethylsiloxane) column (Trace TR-5, $30 \mathrm{~m}$ in length, $0.25 \mathrm{~mm}$ ID, $0.25 \mu \mathrm{m}$ film thickness; Thermo Fisher Scientific Inc., Waltham, MA, USA) and a ThermoQuest Trace 2000 mass spectrometer as detector. The samples, $2 \mathrm{ml}$ of each sample dissolved in $n$-hexane (capillary GC grade; Sigma-Aldrich Chemical Co., St. Louis, MO, USA) were injected in the splitless mode with an inlet temperature of $280{ }^{\circ} \mathrm{C}$. The gas chromatograph was programmed so that the oven temperature was kept at $50{ }^{\circ} \mathrm{C}$ for $3 \mathrm{~min}$, increased to a final temperature of $300{ }^{\circ} \mathrm{C}$ at a rate of $5^{\circ} \mathrm{C} / \mathrm{min}$, and kept at this temperature for $15 \mathrm{~min}$. The carrier gas was helium at $30 \mathrm{~cm} / \mathrm{s}$. Ionization by electron impact $(70 \mathrm{eV})$ was carried out at $220^{\circ} \mathrm{C}$. Mass spectral fragments below $m / z$, 46 were not recorded. Impurities identified in the solvent and/or the control vial samples are not reported. Initial iden- 
tification of secretion components was performed by comparison of sample mass spectra with those in the NIST/EPA/NIH 1998 computerized mass spectral library. When possible, identifications were confirmed by comparison of spectra and retention times with those of authentic standards (from Sigma-Aldrich Chemical Co.).

\section{Results}

A total of 49 lipophilic compounds were identified in femoral gland secretions of male T. merianae (Table I). The main components were carboxylic acids and their esters ranging between $n-\mathrm{C}_{8}$ and $n-\mathrm{C}_{20}(93.9 \%$ of TIC), nineteen steroids $(3.2 \%)$, three forms of tocopherol $(2.1 \%)$, eight aldehydes $(0.7 \%)$, squalene $(0.06 \%)$, and other minor compounds. The major compounds were detected in all individuals, although the relative proportions of some compounds showed interindividual variability. On average, the two most abundant compounds were octadecanoic acid (57.8\% of TIC) and 9,12-octadecadienoic acid $(26.3 \%)$, followed by lower amounts of hexadecanoic acid $(7.3 \%)$, D- $\alpha$-tocopherol $(2.0 \%)$, and cholest-4-en-3-one (1.3\%).

\section{Discussion}

Femoral gland secretions of tegu lizards contain a very high proportion of fatty acids and their esters. Similar fatty acids, but in much lower proportions, have been found in secretions of most other lizard species examined (Weldon et al., 2008). Moreover, it is notorious to find in tegu lizards such a high proportion of octadecanoic and octadecadienoic acids. The function of these fatty acids in femoral gland secretion is unknown, but both fatty acids and their esters are odoriferous and have pheromonal activity in, for example, many insects. Thus, it is likely that these fatty acids also might have a similar function in tegu lizards.

Particularly, it was surprising to find in the secretions large amounts of 9,12-octadecadienoic acid (= linoleic acid). This unsaturated $\omega-6$ fatty acid has been found in secretions of other lizards but always in very small amounts (Weldon et al., 2008). Alberts et al. (1992) found that femoral gland secretions of green iguanas contain a higher abundance of unsaturated fatty acids during the mating season, which may enhance the volatility and detectability of scent marks. Interestingly, analyses of the fatty acids in the fat and muscle tissue of tegu lizards indicated that linoleic acid is one of the more abundant fatty acids, and that it is more abundant in the fat of this lizard than in other animals (Caldironi and Manes, 2006; Ferreira et al., 2009). However, the relative proportion of fatty acids in femoral gland secretions of this lizard is different from that found in its fat (see Ferreira et al., 2009).

However, secretion of large amounts of linoleic acid must be costly for the lizards, because it is one of two essential polyunsaturated fatty acids (linoleic and arachidonic acids) that many animals must ingest for good health. They are required for various biological processes, not just for producing energy, but cannot be synthesized from other food components, and are considered essential fatty acids (Burr et al., 1930). In the skin of vertebrates, they maintain the epidermal water barrier (Hansen and Jensen, 1985) and are metabolized by skin epidermal enzymes generating potent biologically active oxidative metabolites. Linoleic acid is used in the biosynthesis of 8,11,14-eicosatrienoic acid (dihomo- $\gamma$-linolenic acid, DGLA), which is also found in femoral gland secretions of T. merianae. DGLA is transformed into arachidonic acid, and finally into some prostaglandins, hydroxy fatty acids, prostacyclin, and thromboxanes, which mediate many physiological responses and maintain homeostasis and health (Cunnane and Anderson, 1997; Ruthig and Meckling-Gill, 1999; Ziboh et al., 2000).

Given the dietary origin and the important functions of linoleic acid in metabolism, its actual function in femoral gland secretions of T. merianae must be of sufficient importance to divert it from metabolism and "secrete" it from the body. It is likely that only males with an adequate dietary supply could secrete it. As it occurs in other lizard species, the presence of "costly" compounds (e.g. vitamin E, pro-vitamin D) in scent marks of males may be used by females as an index of the quality of a male or of its territory, which can affect female mate choice decisions (Martín and López, 2006a, d, 2011). Nevertheless, the function of linoleic acid and other compounds in secretions of $T$. merianae lizards remains to be analysed properly.

In contrast to the abundance of fatty acids, steroids are relatively little represented in $T$. merianae, whereas steroids are the most abundant compounds in many lacertid or iguanid lizards (Weldon et al., 2008). Particularly noteworthy 
Table I. Lipophilic compounds found in femoral secretions of adult male tegu lizards, Tupinambis merianae. The relative content of each component was determined as the percentage of the total ion current (TIC) and is reported as the average $( \pm \mathrm{SE})$ for eight individuals. Characteristic ions $(\mathrm{m} / \mathrm{z})$ are reported for some unidentified compounds (in brackets).

\begin{tabular}{|c|c|c|}
\hline $\mathrm{RT}^{\mathrm{a}}$ [min] & Compound & Content $(\%)$ \\
\hline 13.1 & Nonenal & $0.01 \pm 0.01$ \\
\hline 15.8 & Octanoic acid & $0.01 \pm 0.01$ \\
\hline 16.2 & Decanal & $0.02 \pm 0.01$ \\
\hline 18.8 & 2,4-Decadienal & $0.06 \pm 0.02$ \\
\hline 19.4 & 2,4-Dodecadienal & $0.06 \pm 0.02$ \\
\hline 28.7 & Tetradecanal & $0.03 \pm 0.01$ \\
\hline 29.9 & Tetradecanoic acid & $0.03 \pm 0.01$ \\
\hline 30.9 & Hexadecanal & $0.37 \pm 0.07$ \\
\hline 31.4 & 6,10,14-Trimethyl-2-pentadecanone & $0.01 \pm 0.01$ \\
\hline 32.0 & Pentadecanoic acid & $0.04 \pm 0.01$ \\
\hline 32.9 & Octadecenal & $0.03 \pm 0.01$ \\
\hline 33.0 & Hexadecanoic acid methyl ester & $0.01 \pm 0.01$ \\
\hline 34.1 & Hexadecanoic acid & $7.34 \pm 0.48$ \\
\hline 34.8 & Octadecanal & $0.13 \pm 0.05$ \\
\hline 35.8 & Heptadecanoic acid & $0.66 \pm 0.14$ \\
\hline 36.1 & 5,8,11-Heptadecatrienoic acid methyl ester & $0.09 \pm 0.03$ \\
\hline 36.2 & 9,12 -Octadecadienoic acid methyl ester & $0.17 \pm 0.07$ \\
\hline 36.8 & Octadecanoic acid methyl ester & $0.01 \pm 0.01$ \\
\hline 37.4 & 9,12-Octadecadienoic acid & $26.26 \pm 2.71$ \\
\hline 37.9 & Octadecanoic acid & $57.78 \pm 2.80$ \\
\hline 40.4 & 8,11,14-Eicosatrienoic acid & $0.84 \pm 0.22$ \\
\hline 40.8 & 4,8,12,16-Tetramethylheptadecan-4-olide & $0.10 \pm 0.04$ \\
\hline 40.9 & Waxy ester of hexadecanoic acid & $0.07 \pm 0.03$ \\
\hline 42.2 & 9,12-Octadecadienoic acid ethyl ester & $0.02 \pm 0.01$ \\
\hline 43.7 & 9,12-Octadecadienoic acid 1-methylethyl ester & $0.03 \pm 0.01$ \\
\hline 44.6 & Unidentified steroid $(133,191,267,337,388)$ & $0.02 \pm 0.01$ \\
\hline 47.3 & Unidentified steroid $(191,204,281,315,357,385,416)$ & $0.02 \pm 0.01$ \\
\hline 47.6 & Squalene & $0.06 \pm 0.01$ \\
\hline 48.1 & Unidentified steroid $(137,153,403,420)$ & $0.05 \pm 0.01$ \\
\hline 48.4 & Unidentified steroid $(137,153,343,369,403,420)$ & $0.06 \pm 0.01$ \\
\hline 48.6 & Cholesta-4,6-dien-3-ol & $0.61 \pm 0.14$ \\
\hline 48.9 & Cholesta-3,5-diene & $0.03 \pm 0.01$ \\
\hline 49.7 & Unidentified form of tocopherol & $0.07 \pm 0.02$ \\
\hline 49.8 & Unidentified steroid $(197,251,376)$ & $0.01 \pm 0.01$ \\
\hline 50.9 & $\gamma$-Tocopherol & $0.05 \pm 0.01$ \\
\hline 51.9 & D- $\alpha$-Tocopherol & $1.99 \pm 0.27$ \\
\hline 52.4 & Cholestan-3-one & $0.07 \pm 0.02$ \\
\hline 53.0 & Cholesta-3,5-dien-7-one & $0.11 \pm 0.02$ \\
\hline 53.3 & Campesterol & $0.05 \pm 0.03$ \\
\hline 53.5 & Cholest-4-en-3-one & $1.26 \pm 0.53$ \\
\hline 53.9 & Cholesta-4,6-dien-3-one & $0.34 \pm 0.08$ \\
\hline 54.1 & 4,22-Cholestadien-3-one & $0.17 \pm 0.04$ \\
\hline 54.2 & Unidentified steroid $(165,191,245,257,369,410,424)$ & $0.01 \pm 0.01$ \\
\hline 54.3 & Waxy ester of octadecenoic acid & $0.48 \pm 0.12$ \\
\hline 54.9 & Unidentified steroid $(257,297,315,340,359,396)$ & $0.01 \pm 0.01$ \\
\hline 55.1 & Cholest-5-en-3-one & $0.06 \pm 0.02$ \\
\hline 55.5 & Unidentified steroid $(173,253,268,368,393)$ & $0.02+0.01$ \\
\hline 55.9 & Cholest-4-ene-3,6-dione & $0.20 \pm 0.05$ \\
\hline 56.5 & Stigmast-4-en-3-one & $0.06 \pm 0.02$ \\
\hline
\end{tabular}

a RT, retention time. 
is the absence of cholesterol in secretions of $T$. merianae, which is ubiquitous and very abundant in many other lizards. Interestingly, the cholesterol content is also lower in meat (see above) of $T$. merianae than in other meats of similar fat content such as beef, chicken or fish (Caldironi and Manes, 2006). In other lizards, cholesterol was thought to serve the purpose of an unreactive apolar matrix in femoral gland secretions that protects and delivers the compounds that are the true semiochemicals (Escobar et al., 2003). A possible explanation of the absence of cholesterol in tegu lizards is the presence of abundant keratin in the secretion cylinders (Chamut et al., 2009). The keratin sheets and epithelial layers that surround the secretions form a sort of structural support for lipophilic secretions. Keratin may have a role similar to cholesterol in protecting lipids after secretion cylinders have been abraded on the substrate.

We also found in secretions of T. merianae tocopherol and squalene, two well known lipophilic antioxidants (Brigelius-Flohe and Traber, 1999). Their main possible function in secretions might be to inhibit oxidation of other lipids in secretions (see Alberts, 1992), as it occurs in lacertid green lizard species inhabiting wet environments (López and Martín, 2006; Kopena et al., 2009; Martín and López, 2010b).

Alberts A. C. (1992), Constraints on the design of chemical communication systems in terrestrial vertebrates. Am. Nat. 139, 62-89.

Alberts A. C. (1993), Chemical and behavioral studies of femoral gland secretions in iguanid lizards. Brain Behav. Evol. 41, 255-260.

Alberts A. C., Sharp T. R., Werner D. I., and Weldon P. J. (1992), Seasonal variation of lipids in femoral gland secretions of male green iguanas, Iguana iguana. J. Chem. Ecol. 18, 703-712.

Aragón P., López P., and Martín J. (2001), Chemosensory discrimination of familiar and unfamiliar conspecifics by lizards: implications of field spatial relationships between males. Behav. Ecol. Sociobiol. 50, 128-133.

Brigelius-Flohe R. and Traber M. G. (1999), Vitamin E: function and metabolism. FASEB J. 13, 1145-1155.

Burr G. O., Burr M. M., and Miller E. (1930), On the nature of the fatty acids essential in nutrition. J. Biol. Chem. 86, 587-621.

Caldironi H. A. and Manes M. E. (2006), Proximate composition, fatty acids and cholesterol content of meat cuts from tegu lizard Tupinambis merianae. J. Food Comp. Anal. 19, 711-714.
Finally, we also found many aldehydes in the secretions. These are highly odoriferous compounds that might contribute to make the detection of femoral gland secretions easier after they have been deposited. Aldehydes have also been found in some other lizard species, but not in other species even if these were included within the same genus (Weldon et al., 2008), so their presence in secretions might depend on the environment or social behaviour of the respective species.

Further studies are clearly needed to understand the patterns of the presence and abundance of different compounds in femoral gland secretions of lizards, and how phylogenetic relationships and environmental conditions can explain the characteristics of these secretions. Also, we need to clarify the possible role of the compounds found in femoral gland secretions as potential signaling pheromones, such as linoleic acid, in social organization and sexual selection processes of tegu lizards.

\section{Acknowledgements}

Financial support was provided by the Spanish project MCI-CGL2008-02119/BOS and by the Research Council of the National University of Tucumán.

Carazo P., Font E., and Desfilis E. (2007), Chemosensory assessment of rival competitive ability and scent mark function in a lizard (Podarcis hispanica). Anim. Behav. 74, 895-902.

Cei J. M. and Scolaro J. A. (1982), A population of Tupinambis from northern Patagonia south of the Rio Negro, Argentina. Herpetol. Rev. 13, 26-29.

Chamut S., García Valdez V., and Manes M. E. (2009), Functional morphology of femoral glands in the tegu lizard, Tupinambis merianae. Zool. Sci. 26, 289-293.

Cunnane S. and Anderson M. (1997), Pure linoleate deficiency in the rat: influence on growth, accumulation of $n-6$ polyunsaturates, and $(1-14 C)$ linoleate oxidation. J. Lipid Res. 38, 805-812.

Escobar C. A., Labra A., and Niemeyer H. M. (2001), Chemical composition of precloacal secretions of $\mathrm{Li}$ olaemus lizards. J. Chem. Ecol. 27, 1677-1690.

Escobar C. M., Escobar C. A., Labra A., and Niemeyer H. M. (2003), Chemical composition of precloacal secretions of two Liolaemus fabiani populations: are they different? J. Chem. Ecol. 29, 629-638.

Ferreira F. S., Brito S. V., Costa J. G. M., Alves R. R. N., Coutinho H. D. M., and Almeida W. O. (2009), Is the 
body fat of the lizard Tupinambis merianae effective against bacterial infections? J. Ethnopharmacol. 126, 233-237.

Fitzgerald L. A., Chani J. M., and Donadio O. E. (1991), Tupinambis lizards in Argentina: implementing management of a traditionally exploited resource. In: Neotropical Wildlife: Use and Conservation (Robinson J. and Redford K., eds.). University of Chicago Press, Chicago, pp. 303-316.

Fitzgerald L. A., Cook J. A., and Aquino A. L. (1999), Molecular phylogenetics and conservation of Tupinambis (Sauria: Teiidae). Copeia 1999, 894-905.

Gabirot M., López P., Martín J., de Fraipont M., Heulin B., Sinervo B., and Clobert J. (2008), Chemical composition of femoral secretions of oviparous and viviparous types of male common lizards Lacerta vivipara. Biochem. Syst. Ecol. 36, 539-544.

Hansen H. S. and Jensen B. (1985), Essential function of linoleic acid esterified in acylglucosylceramide and acylceramide in maintaining the epidermal water permeability barrier. Evidence from feeding studies with oleate, linoleate, arachidonate, columbinate, and $\alpha$-linolate. Biochim. Biophys. Acta 834, 357-363.

Kopena R., López P., and Martín J. (2009), Lipophilic compounds from the femoral gland secretions of male Hungarian green lizards, Lacerta viridis. Z. Naturforsch. 64c, 434-440.

López P. and Martín J. (2005a), Female Iberian wall lizards prefer male scents that signal a better cellmediated immune response. Biol. Lett. 1, 404-406.

López P. and Martín J. (2005b), Age related differences in lipophilic compounds found in femoral gland secretions of male spiny-footed lizards, Acanthodactylus erythrurus. Z. Naturforsch. 60c, 915-920.

López P. and Martín J. (2005c), Chemical compounds from femoral gland secretions of male Iberian rock lizards, Lacerta monticola cyreni. Z. Naturforsch. 60c, 632-636.

López P. and Martín J. (2006), Lipids in the femoral gland secretions of male Schreiber's green lizards, Lacerta schreiberi. Z. Naturforsch. 61c, 763-768.

López P. and Martín J. (2009), Lipids in femoral gland secretions of male lizards, Psammodromus hispanicus. Biochem. Syst. Ecol. 37, 304-307.

López P., Muñoz A., and Martín J. (2002), Symmetry, male dominance and female mate preferences in the Iberian rock lizard, Lacerta monticola. Behav. Ecol. Sociobiol. 52, 342-347.

López P., Aragón P., and Martín J. (2003), Responses of female lizards, Lacerta monticola, to males' chemical cues reflect their mating preference for older males. Behav. Ecol. Sociobiol. 55, 73-79.

López P., Amo L., and Martín J. (2006), Reliable signaling by chemical cues of male traits and health state in male lizards, Lacerta monticola. J. Chem. Ecol. 32, 473-488.

Louw S., Burger B. V., Le Roux M., and Van Wyk J. H. (2007), Lizard epidermal gland secretions I: chemical characterization of the femoral gland secretion of the sungazer, Cordylus giganteus. J. Chem. Ecol. 33, $1806-1818$.

Manes M. E., Noriega T., Campos-Casal F., and Apichela S. (2007), Ovarian changes during the reproductive cycle of the Tupinambis merianae lizard raised in a temperate environment. Cuad. Herpetol. 21, 21-29.
Martín J. and López P. (2000), Chemoreception, symmetry and mate choice in lizards. Proc. R. Soc. London Ser. B 267, 1265-1269.

Martín J. and López P. (2006a), Links between male quality, male chemical signals, and female mate choice in Iberian rock lizards. Funct. Ecol. 20, 1087-1096.

Martín J. and López P. (2006b), Interpopulational differences in chemical composition and chemosensory recognition of femoral gland secretions of male lizards Podarcis hispanica: implications for sexual isolation in a species complex. Chemoecology 16, 31-38.

Martín J. and López P. (2006c), Age-related variation in lipophilic chemical compounds from femoral gland secretions of male lizards Psammodromus algirus. Biochem. Syst. Ecol. 34, 691-697.

Martín J. and López P. (2006d), Vitamin D supplementation increases the attractiveness of males' scent for female Iberian rock lizards. Proc. R. Soc. London Ser. B 273, 2619-2624.

Martín J. and López P. (2010a), Condition-dependent pheromone signalling by male rock lizards: more oily scents are more attractive. Chem. Senses 35, 253-262.

Martín J. and López P. (2010b), Multimodal sexual signals in male ocellated lizards Lacerta lepida: vitamin $\mathrm{E}$ in scent and green coloration may signal male quality in different sensory channels. Naturwissenchaften 97, 545-553.

Martín J. and López P. (2011), Pheromones and reproduction in reptiles. In: Hormones and Reproduction of Vertebrates, Vol. 3, Reptiles (Norris D. O. and Lopez K. H., eds.). Academic Press, San Diego, CA, USA, pp. $141-167$.

Martín J., Civantos E., Amo L., and López P. (2007a), Chemical ornaments of male lizards Psammodromus algirus may reveal their parasite load and health state to females. Behav. Ecol. Sociobiol. 62, 173-179.

Martín J., Moreira P. L., and López P. (2007b), Statussignalling chemical badges in male Iberian rock lizards. Funct. Ecol. 21, 568-576.

Mason R. T. (1992), Reptilian pheromones. In: Biology of the Reptilia, Vol. 18 (Gans C. and Crews D., eds.). University of Chicago Press, Chicago, pp. 114-228.

Mason R. T. and Parker M. R. (2010), Social behavior and pheromonal communication in reptiles. J. Comp. Physiol. A 196, 729-749.

Mercolli C. and Yanosky A. A. (1989), Répertoire des comportements du Téju (Tupinambis teguixin) Sauria: Teiidae. Rev. Fr. Aquariol. Herpetol. 16, 123-130.

Noriega T., Fogliatto O., Mignola L., and Manes M. E. (1996), Ciclo biológico y patrones de comportamiento en una población de iguanas overas Tupinambis teguixin (L) (Sauria, Teiidae) adaptada al cautiverio. Rev. Agron. Noroeste Argent. 28, 109-127.

Noriega T., Ibáñez M. A., Bru E., and Manes M. E. (2002), The testicular cycle of captive Tupinambis merianae lizards in a temperate environment. Cuad. Herpetol. 16, 119-127.

Olsson M., Madsen T., Nordby J., Wapstra E., Ujvari B., and Wittsell H. (2003), Major histocompatibility complex and mate choice in sand lizards. Proc. R. Soc. London Ser. B (Suppl.) 270, 254-256.

Presch W. (1973), A review of the Tegu, lizard genus Tupinambis (Sauria: Teiidae) from South America. Copeia 1973, 740-746. 
Ruthig D. J. and Meckling-Gill K. A. (1999), Both (n-3) and (n-6) fatty acids stimulate wound healing in the rat intestinal epithelial cell line, IEC-6. J. Nutr. 129, $1791-1798$.

Vega Parry H. E. and Manes M. E. (2000), Alimentación de lagartos overos Tupinambis merianae con subproductos avícolas. Rev. Argentina Prod. Anim. 20, $135-143$.

Weldon P. J., Dunn B. S., McDaniel C. A., and Werner D. I. (1990), Lipids in the femoral gland secretions of the green iguana (Iguana iguana). Comp. Biochem. Physiol. B 95, 541-543.

Weldon P. J., Flachsbarth B., and Schulz S. (2008), Natural products from the integument of nonavian reptiles. Nat. Prod. Rep. 25, 738-756.

Ziboh V. A., Miller C. C., and Cho Y. (2000), Significance of lipoxygenase-derived monohydroxy fatty acids in cutaneous biology. Prostaglandins Lipid Med. 63, 3-13. 